\title{
Multiple sclerosis in Kuwait: clinical and epidemiological study
}

\author{
AMIR S NAJIM AL-DIN \\ From the Department of Medicine, Faculty of Medicine, Kuwait University, Kuwait
}

SUMMARY Eighty-nine cases of multiple sclerosis (70 Arabs) are reported from Kuwait. The prevalence is estimated to be 8.33 per 100000 (age and sex adjusted to USA population). Kuwait thus emerges to be in the medium risk zone. No differences were found in the age of onset, clinical pattern and disability from the disease found in Europeans and North Americans.

More than 200 epidemiological studies of multiple sclerosis have been cited by Kurtzke. ${ }^{1}$ Few of these were from the Middle East. ${ }^{2-7}$

Kuwait is a small country occupying the north western corner of the Arabian Gulf, located between latitudes $28^{\circ} 45^{\prime}$ and $30^{\circ} 05^{\prime}$ to the north of the equator and longitudes $46^{\circ} 30^{\prime}$ and $48^{\circ} 30^{\prime}$ to the east of Greenwich. The weather is typical of the Sahara geographical region; winter is short and cool with a mean maximum temperature of $17.4^{\circ} \mathrm{C}$ and mean minimum temperature of $7.7^{\circ} \mathrm{C}$ in January. Summer is long and hot with a mean maximum temperature of $46.6^{\circ} \mathrm{C}$ in July. The country is generally flat. ${ }^{8}$ The population of Kuwait in 1980 was 1355827 . The indigenous population was $562065(41 \cdot 4 \%)$, the rest belonging to 120 countries; Palestinians 320000 (23.6\%), Egyptians $186000(13.7 \%)$, Iraqis $46000(3.39 \%)$, Iranians $42000(3.09 \%)$ and $70000(5 \cdot 16 \%)$ from the Indian subcontinents. ${ }^{8}$ Almost all the population live in the three major cities, which are near to each other. The Kuwaitis have a better standard of living, housing and sanitation than the non Kuwaitis. ${ }^{9}$

Immigration to and from Kuwait is a dynamic process but the bulk of the immigrants are Palestinians (from the West Bank and the Gaza Strip) and Egyptians. Most of the Palestinians immigrated in the 1960 s and they tend to settle, the rest immigrated fairly recently. ${ }^{9}$

Kuwait has a well organised free medical service covering the whole country, and interchange of data between the different hospitals is easy. There is 1 doctor per 666 people. $^{10}$

\footnotetext{
Address for reprint requests: Dr Amir S Najim Al-Din, Department of Medicine, Faculty of Medicine, Kuwait University, PO Box 24923, Kuwait.
}

Received 9 August 1985.

Accepted 2 November 1985

\section{Patients and methods}

A preliminary period of data collection was set up for three years (1981-1983) to identify cases of multiple sclerosis in Kuwait. The material was based on referrals to Ibn Sina Hospital (the neurology and neurosurgery centre of Kuwait) and cases seen in the two other neurology units in Mubarak Al-Kabeer and Al-Emirie Hospitals. The consultant physicians in all hospitals were made aware of the study and asked to refer patients in whom they suspected multiple sclerosis. A minimum period of follow up of one year in our department was considered necessary, thus the final period of the study was the year 1983-1984. Patients presenting for the first time in 1984 were not included. Patients included had to be Kuwaitis or residents in Kuwait. Those coming for the sake of medical care and not eventually settling in $\mathrm{Ku}$ wait were not included.

Data were available on 95 patients with multiple sclerosis but only 89 were contactable for evaluation. A detailed history was obtained including the country of origin, place of birth, age at immigration for the non Kuwaitis, age of onset and duration of illness. Also included were a detailed history of the disease, pattern of progress and response to the different therapeutic measures. All were investigated as inpatients. Haematological and biomechemical profiles were performed on all patients, so were a collagen screen, serological tests for syphilis, computed tomography of the head (CT) and pattern reversal visual evoked responses (VERs). The cerebro-spinal fluid (CSF) was studied at least once in 87 patients. The test included cell count, estimation of protein, sugar, IgG levels, and serological tests for syphilis. Myelography or any other specialised investigation were performed if indicated.

The diagnostic criteria were those of Poser et al $^{11}$ dividing patients into the following: (1) Clinically definite. Two attacks and clinical evidence of two separate lesions or two attacks with clinical evidence of one lesion and paraclinical evidence of another, separate lesion. (2) Laboratorysupported definite multiple sclerosis. Two attacks with either clinical or paraclinical evidence of one lesion and CSF oligoclonal bands (OB)/IgG, or, one attack with clinical evidence of two separate lesions, and CSF OB/IgG or, one 
Table 1 Distribution of patients according to country of origin and sex

\begin{tabular}{|c|c|c|c|c|c|c|c|}
\hline Country & Number & $M$ & $F$ & Country & Number & $M$ & $\boldsymbol{F}$ \\
\hline $\begin{array}{l}\text { Kuwait } \\
\text { Palestine } \\
\text { Iraq } \\
\text { Egypt } \\
\text { Syria } \\
\text { Lebanon } \\
\text { Bahrain } \\
\text { Saudi Arabia } \\
\text { Sudan }\end{array}$ & $\begin{array}{r}27 \\
25 \\
8 \\
6 \\
4 \\
2 \\
2 \\
1 \\
1\end{array}$ & $\begin{array}{r}13 \\
14 \\
5 \\
1 \\
1 \\
1 \\
2 \\
1 \\
1\end{array}$ & $\begin{array}{r}14 \\
11 \\
3 \\
5 \\
3 \\
1 \\
- \\
- \\
-\end{array}$ & $\begin{array}{l}\text { Somalia } \\
\text { Iran } \\
\text { India } \\
\text { Pakistan } \\
\text { Italy } \\
\text { Bulgaria } \\
\text { UK } \\
\text { USA } \\
\text { Total }\end{array}$ & $\begin{array}{r}1 \\
4 \\
2 \\
1 \\
1 \\
1 \\
1 \\
2 \\
89\end{array}$ & $\begin{array}{l}1 \\
3 \\
2 \\
1 \\
1 \\
- \\
- \\
47\end{array}$ & $\begin{array}{r}-1 \\
- \\
- \\
1 \\
1 \\
2 \\
42\end{array}$ \\
\hline
\end{tabular}

attack with clinical evidence of one lesion and paraclinical evidence of another, separate lesion and CSF OB/IgG. (3) Clinically probable multiple sclerosis (CPMS). Two attacks and clinical evidence of one lesion, or one attack and clinical evidence of two separate lesions, or one attack with clinical evidence of one lesion and paraclinical evidence of another, separate lesion. (4) Laboratory-supported probable multiple sclerosis (LSPMS). Two attacks and CSF OB/IgG.

Disability was assessed according to the disability scale of Kurtzke, ${ }^{12}$ based on mobility, visual impairment, ability to maintain a job, bladder and sexual functions.

Each patient was followed up for the period of the study by the author or a colleague neurologist and reviewed by the author at the end of the study.

\section{Results}

Ninety five patients satisfied the criteria of Poser $e t$ $a l ;{ }^{11}$ only 89 were available for examination and eventual follow up. They belonged to 17 countries: 9 were Arabic and 8 non Arabic, 27 Kuwaitis, 25 Palestinians and 37 from 15 other countries (table 1). They were of nine ethnic groups: 70 Arabs and 19 non Arabs (table 2).

Two of the patients, both Kuwaitis, died during the period of the study. Thus, a minimum prevalence rate seems to be 6.42 per $100000 ; 4.44$ for Kuwaitis, 7.8 (unadjusted figure) for Palestinians. The prevalence rate for the non Kuwaitis age and sex adjusted to Kuwaitis was $7 \cdot 29$. If the prevalence rate for Kuwait was corrected for a standard population (USA) the

Table 2 Distribution of patients according to nationality and $\operatorname{sex}(n=89)$

\begin{tabular}{lrcc}
\hline & & Males & Females \\
\hline Arabs & 70 & 34 & 36 \\
Iranian & 8 & 8 & - \\
Armenian & 3 & -3 & - \\
Indian sub continent & 3 & 1 & - \\
Somalian & 1 & 1 & - \\
Italian & 1 & - & 1 \\
Bulgarian & 1 & - & 1 \\
American & 1 & - & 1 \\
British & 1 & & \\
\hline
\end{tabular}

rate became 8.33 per 100000 .

There were 47 males and 42 females $(M: F$ ratio of $1 \cdot 11: 1)$ but variations existed in the different population groups (tables 1 and 2). In the non Kuwaitis there were 34 males and 28 females, 13 of the 19 non Arab patients were males. The age at the end of the study was 15-59 years (mean 34.3); 18-59 years (mean 35.2) for males, and 15-50 years (mean 33.3) for females, with no differences in the different nationality or ethnic groups. The age of onset was 12-50 years (mean 27.5) in the whole group; 14-50 (mean 29.4) for males and 12-44 (mean 25.7) for females. Sixty-two $(69.6 \%)$ presented between the ages of 20-40.

Four of the non Kuwaitis were born in Kuwait, three Palestinians and one Iraqi; two immigrated before the age of 15 years. In the rest the age at immigration was 15-46 years (mean 23.9). Thirteen of the non Kuwaitis had their first symptom prior to moving to Kuwait. In the other 45 there was a mean period of stay of 9.75 years prior to the first symptom; 11.7 for Palestinians and 7.8 for the rest.

Weakness of the lower limbs was the presenting symptom in $31(34.8 \%)$, blurring of vision in 24 $(26.9 \%)$, sensory symptoms in $16(17.9 \%)$ and multiple symptoms in $4(4 \cdot 4 \%)$.

Clinical evaluation revealed the presence of balance abnormalities and ataxia in $60(67.4 \%)$, impaired sensation and paraesthesiae in $55(61.7 \%)$, paraparesis in $53(59 \cdot 5 \%)$, blurring of vision and optic neuritis in 44 $(49 \cdot 4 \%)$ (table 3 ) with no differences in the different nationality or ethnic groups.

Sixty-eight had clinically definite multiple sclerosis $(76.4 \%)$ two of whom had Devic's syndrome, 4 laboratory supported clinically definite multiple sclerosis and 17 clinically probable multiple sclerosis. Twentytwo of the patients with clinically definite multiple sclerosis were Kuwaitis, 20 Palestinians and 26 from the other countries (54 Arabs and 14 non Arabs). Seventy-seven $(86.5 \%)$ of the patients had a remitting and relapsing disease, and $12(13.4 \%)$ a progressive one. Nine of the remitting and relapsing group eventually had a progressive illness with a mean duration of illness of 10.5 years. 
Table 3 Neurological symptoms and signs during the course of illness $(n=89)$

\begin{tabular}{|c|c|c|c|}
\hline $\begin{array}{l}\text { Balance abnormalities and ataxia } \\
\text { Impaired sensation } \\
\text { Paraparesis } \\
\text { Optic neuritis }\end{array}$ & $\begin{array}{l}60(67 \cdot 4 \%) \\
55(61 \cdot 7 \%) \\
53(59 \cdot 5 \%) \\
44(49 \cdot 4 \%)\end{array}$ & $\begin{array}{l}\text { Micturition changes } \\
\text { Impotence } \\
\text { Giddiness } \\
\text { Epilepsy } \\
\text { Tic douloreux }\end{array}$ & $\begin{array}{c}38(42 \cdot 6 \%) \\
10(11 \cdot 2 \%) \\
9(10 \cdot 1 \%) \\
1(1 \cdot 1 \%) \\
1(1 \cdot 1 \%)\end{array}$ \\
\hline
\end{tabular}

The duration of illness was 1-24 years (mean 6.73); 6.2 years for males and 7.3 for females. It was longer in the Kuwaitis and Palestinians than in the rest.

Sixty $(67.5 \%)$ patients were still able to walk without help, $23(25.8 \%)$ walking with aids, and $4(4 \cdot 5 \%)$ were restricted to a wheel chair. The mean age of onset was $27.2,30.6$ and 20.7 years respectively and the mean duration of illness was $6 \cdot 26,7.91$ and $9 \cdot 5$ years respectively. The four patients restricted to a wheel chair were females; three Kuwaitis and one Palestinian. Apart from this group of severely disabled patients the minimally and moderately disabled patients showed a nearly equal sex ratio. Two patients died during the period of the study, both Kuwaitis. Both died from causes unrelated to their multiple sclerosis. No postmortem study was available.

The CSF was studied in 87 patients and was abnormal in $59(67.8 \%)$ the commonest abnormality was a high CSF IgG content. The VERs were done in 87 and were abnormal in $81(93 \cdot 1 \%)$, CT was done in 86 and was reported as abnormal, showing atrophy or plaque in $32(37 \cdot 2 \%)$.

\section{Discussion}

The world wide distribution of multiple sclerosis seems to comprise three zones of high, medium, and low risk or frequency. ${ }^{13}$ The prevalence rates reported are 30 or more per 100000 population for the high risk zone, 5-29 for the medium risk zone, and less than 5 per 100000 population for the low risk zone. Kurtzke ${ }^{1}$ reviewed over 50 surveys from the Mediterranean basin, all falling within the medium risk zone. Few studies are available from the Middle East and in particular in Arabs. ${ }^{2-4}$ Israel falls in the medium risk zone ${ }^{14}$ and multiple sclerosis there seems to be commoner in immigrants from Central and Northern Europe than from the Near East and Africa. $^{6}$

Kuwait is ideal for the study of the prevalence of multiple sclerosis because it is a small country where the majority of the population lives in a small part of it, making data collection easier. Medical services have tremendously expanded in the last five years, but there are factors which have to be considered in assessing the prevalence in the different population groups. Firstly, the immigrant population of Kuwait have a different age and sex pattern from the $\mathrm{Ku}$ - waitis. Secondly only healthy people seek immigration thus leaving behind those already affected, especially if disabled. Thirdly there is counter immigration of disabled people to their homeland in the absence of social security, but this does not apply to the Palestinians who have lost their homeland.

The diagnosis of multiple sclerosis requires a high degree of medical expertise, thus the prevalence rates do not reflect incidence rates but also, to a great extent the quality of medical treatment, recording, and reporting. ${ }^{15}$ Clearly an incidence rate cannot be deduced as the cases presented in this paper are aggregates from previous years. As two patients died during the period of the study, both Kuwaitis, the minimum prevalence rate seems to be 6.42 per 100000 (8.33 if age and sex corrected to USA population), 4.44 for Kuwaitis, 7.8 (unadjusted figure) for Palestinians. The prevalence rate for the non Kuwaitis age and sex adjusted to Kuwaitis was 7.29 per 100000 (none, but the total prevalence is corrected to a standard population). This latter figure (prevalence in non Kuwaitis) is artificially low because of the factors already mentioned. This puts Kuwait in the medium risk zone, and although the number of patients is too small to draw firm conclusions, it seems that possible different risk zones exist in the Middle East, Kuwait being relatively lower than Palestine.

Four of the 62 non Kuwaiti patients were born in Kuwait and only two immigrated below the age of 15 years. It is possible that the remaining 56 carry with them the same risk factor applicable to their countries. Eighteen of the Palestinians immigrated from the West Bank; 12 from the Ram Allah and Tulkerim areas, north east of Jerusalem. As immigrants from this area represent less than $30 \%$ of Palestinians in Kuwait the above figure might reflect a focus of high incidence. It is not possible to draw conclusions regarding the prevalence in the other nationality groups, Arabs and non Arabs, because the number of patients is too small and because their immigration to Kuwait is more recent than the Palestinians'.

The disease behaved in a similar way to that seen in Europe and North America. The age of onset $(69.6 \%$ presented between 20-40) was similar to those of Kurtzke $^{16}$ and McAlpine et $a l^{17}$ patients. The fact that there were more males than females in this report is readily explainable on the structure of the population. There are far more adult males than females 
in a predominantly immigrant population. The presenting symptoms were fairly similar to those reported in the Western countries. ${ }^{18-20}$ Unlike the cases reported from Japan ${ }^{21}$ and some other parts of Asia ${ }^{22}$ bilateral simultaneous involvement of visual acuity was only seen in $2(2 \cdot 4 \%)$ compared to $11 \%$. The neurological symptoms and signs reported in this series (table 3) differed little from Muller's ${ }^{23}$ cases and the US army series. ${ }^{24} \mathrm{~A}$ remitting and relapsing pattern was the usual $(86.5 \%)$. Neuromyelitis optica was uncommon. The disease was not any more or less disabling than in McAlpine and Compston's ${ }^{25}$ patients.

Multiple sclerosis does occur in the Middle East, affecting Arabs in no way different from Europeans, but less frequently. It seems to be the same disease as in Europe and was different from cases reported from Japan and South East Asia.

An immunogenetic study of some of the patients in this series is under way to investigate any association or lack of association between the disease and the different HLA DR epitopes.

It is hoped that in the future other epidemiological studies from other parts of the Arab world will appear to clarify the situation in an area of the world and an ethnic group in which multiple sclerosis is not well studied.

I am indebted to Dr R Shakir and Dr J Hussain for allowing me to use their clinical material and to all the staff in the Neurology Department in Ibn Sina and Al-Emirie Hospitals for their help.

\section{References}

${ }^{1}$ Kurtzke JF. Geographic distribution of multiple sclerosis. An update with special reference to Europe and the Mediterranean region. Acta Neurol Scand 1980;62: 65-80.

${ }^{2}$ Shaby JA. Multiple sclerosis in Iraq. Wien Z Nervenheilk 1958;15:276-83.

${ }^{3}$ Hamdi TI. Multiple sclerosis in Iraq: A clinical and geomedical survey. J Postgrad Med 1975;21:1-9.

${ }^{4}$ Kurdi A, Ayesh I, Abdallat A, Mcdonald WI. Multiple sclerosis and IA-like antigens in Jordan. Presented to the 11th World Congress of Neurology, Amsterdam, 1977.

${ }^{5}$ Mutlu M. The effect of geographic and meteorological factors on the incidence of multiple sclerosis in Turkey. Acta Neurol Scand 1960;35 (Suppl 147).

${ }^{6}$ Alter M, Harpen L, Kurland T, et al. Multiple sclerosis in Israel. Prevalence among immigrants and native inhabitants. Arch Neurol 1962;7:253-63.
${ }^{7}$ Leibowitz U, Kahana E, Alter M. Multiple sclerosis in Israel. Epidemiological considerations. Israel J Med Sci 1971:1562-7.

${ }^{8}$ Annual Statistical Abstract. Ministry of Planning, State of Kuwait. Vol 11. 1982.

${ }^{9}$ Al-Feel MR. The Population of Kuwait, 2nd ed, Cairo: Wakalat Al-Matbuat, 1972.

${ }^{10}$ Kurtz RA. Changing characteristics among medical doctors in Kuwait, 1971-1981. J Kut Med Assoc 1984; 18:5-21.

${ }^{11}$ Poser CM, Paty DW, Scheinberg L, et al. New Diagnostic Criteria for Multiple Sclerosis: Guidelines for Research Protocols. Ann Neurol 1983;13:227-31.

${ }^{12}$ Kurtzke JF. On the evaluation of disability in mutiple sclerosis. Neurology (Minneap) 1961;11:686-94.

${ }^{13}$ Kurtzke JF. A reassessment of the distribution of multiple sclerosis. Part one and part two. Acta Neurol Scand 1975;51:110-35, 137-57.

${ }^{14}$ Leibowitz U, Kahana E, Alter M. Population studies in Israel. Field EJ, Bell TM, Carnegie PR, eds. Multiple Sclerosis. Progress in Research. Amsterdam: NorthHolland Publ Co, 1972:196-7.

${ }^{15}$ Leibowitz U. Multiple Sclerosis: Progress in epidemiologigic and experimental research. A review. $J$ Neurol Sci 1971;12:307-18.

${ }^{16}$ Kurtzke JF. Clinical manifestations of multiple sclerosis. In: Vinken PJ, Bruyn GW, eds. Handbook of Clinical Neurology, vol 19. Amsterdam: North-Holland Publishing Company, 1970:161-201.

${ }^{17}$ McAlpine D, Lumsden CE, Acheson ED. Multiple Sclerosis. A Reappraisal. 2nd ed. London: Churchill Livingstone, 1972:83-307.

${ }^{18}$ Adams DK, Sutherland JM, Fletcher WB. Early clinical manifestations of disseminated sclerosis. $\mathrm{Br}$ Med $\mathrm{J}$ 1950;2:431-6.

${ }^{19}$ Ivers RR, Goldstein NP. Multiple sclerosis: A current appraisal of symptoms and signs. Mayo Clin Proc 1963;38:457-66.

${ }^{20}$ Poser CM, Persthus J, Horsdal O. Clinical characteristics of autopsy proved multiple sclerosis. A study of British, Norwegian, and American cases. Neurology (Minneap) 1966;16:791-8.

${ }^{21}$ Kuroiwa Y, Igata A, Itahara K, et al. Nationwide survey of multiple sclerosis in Japan: clinical analysis of 1,084 cases. Neurology (Minneap) 1975;25:845-51.

${ }^{22}$ Kuroiwa Y; Hung TP, Landsborough D, et al. Multiple sclerosis in Asia. Neurology (Minneap) 1977;27:188-92.

${ }^{23}$ Muller R. Studies on dissemenated sclerosis with special reference to symptomatology, course and prognosis. Acta Scand (Suppl 222), 1949;133:1-214.

${ }^{24}$ Kurtzke JF, Beebe G, Nagler B, et al. Studies on the natural history of multiple sclerosis: 6 . Clinical and laboratory findings at first diagnosis. Acta Neurol Scand 1972;48:19-46.

${ }^{25}$ McAlpine D, Compston ND. Some aspects of the natural history of dissemenated sclerosis. $Q J$ Med 1952; 21:135-67. 